\title{
Deriva de Herbicidas e Efeito de Fungicida u Herbicida em Plantas Jovens de Pessegueiro ${ }^{1}$
}

\author{
Herbicide Drift Simulation and Effect of Fungicide u Herbicide on Peach Tree Seedlings
}

\author{
TUFFI SANTOS, L.D. ${ }^{2}$, WAGNER JÚNIOR, A. ${ }^{2}$, SILVA, J.O.C. ${ }^{3}$, PIMENTEL, L.D. ${ }^{3}$, \\ SANTOS, C.E.M. ${ }^{4}$, BRUCKNER, C.H. ${ }^{5}$ e FERREIRA, F.A. ${ }^{5}$
}

\begin{abstract}
RESUMO - O objetivo deste trabalho foi avaliar os efeitos da deriva de glyphosate e triclopyr sobre plantas jovens de pessegueiro, bem como o comportamento destas quando submetidas à deriva de glyphosate com tratamento prévio de fungicida. No experimento 1 , a simulação da deriva foi feita por aplicação de subdoses dos herbicidas glyphosate $(43,2 ; 86,4 ; 172,8$; e $\left.345,8 \mathrm{~g} \mathrm{ha}^{-1}\right)$, triclopyr $\left(14,4 ; 28,8 ; 57,6 ;\right.$ e $\left.115,2 \mathrm{~g} \mathrm{ha}^{-1}\right)$ e pela mistura de glyphosate + triclopyr $\left(43,2+24,4 ; 86,4+28,8 ;\right.$ e $172,8+57,6$ g ha $\left.^{-1}\right)$, constituindo os tratamentos. O experimento 2 foi num fatorial 2 × 6 [fungicida (presença e ausência de aplicação) x subdoses de glyphosate $\left(0 ; 43,2 ; 86,4 ; 129,6 ; 172,8 ;\right.$ e $\left.\left.345,6 \mathrm{~g} \mathrm{ha}^{-1}\right)\right]$. No experimento 1 , plantas tratadas com glyphosate e triclopyr nas doses de 345,6 e 57,6 g e.a. ha ${ }^{-1}$, respectivamente, apresentaram maiores percentuais de intoxicação, não havendo efeito da deriva destes herbicidas no desenvolvimento inicial. No experimento 2, as doses de glyphosate influenciaram o desenvolvimento inicial das plantas, com efeitos proporcionais ao aumento das doses. O fungicida não influenciou o desenvolvimento inicial, mas a porcentagem de intoxicação foi maior em plantas tratadas, indicando possivel efeito sinérgico entre os defensivos testados.
\end{abstract}

Palavras-chave: Prunus persica, fitointoxicação, herbicida.

\begin{abstract}
The aim of this work was to evaluate the effects of glyphosate and triclopyr drift on the initial growth of peach tree seedlings, as well as the behavior of these seedlings when submitted to glyphosate drift with fungicidal treatment. In Experiment 1, simulation drift was performed by applying glyphosate $\left(43.2 ; 86.4 ; 172.8\right.$ and $\left.345.8 \mathrm{~g} \mathrm{ha}^{-1}\right)$, triclopyr (14.4; 28.8; 57.6 and $\left.115.2 \mathrm{~g} \mathrm{ha}^{-1}\right)$ and the mixture glyphosate + triclopyr $(43.2+24.4 ; 86.4+28.8$ and $\left.172.8+57.6 \mathrm{~g} \mathrm{ha}^{-1}\right)$, as the treatments. Experiment 2 was arranged in a $2 \times 6$ factorial scheme [fungicide (with and without of application) $x$ reduced rates of glyphosate $(0 ; 43.2 ; 86.4 ; 129.6$; 172.8 and $\left.345.6 \mathrm{~g} \mathrm{ha}^{-1}\right)$. In Experiment 1, peach seedlings treated with glyphosate and triclopyr; $345.6 \mathrm{~g}$ and $57.6 \mathrm{~g} \mathrm{ha}^{-1}$, respectively, presented the highest intoxication percentage, with no drift effect being verified on plant growth. In Experiment 2, the glyphosate doses applied influenced initial plant growth, with the effects being proportional to increase of the doses. The fungicide did not influence peach seedling growth, but the intoxication percentage was higher in the plants treated, indicating a possible synergistic effect among the herbicides tested.
\end{abstract}

Keywords: Prunus persica, plant intoxication, herbicide.

\section{INTRODUÇÃO}

A produção brasileira de pêssegos no ano de 2002 foi de 218.292 toneladas. Essa produção ainda é insuficiente para atender à demanda interna. O Brasil importou nesse mesmo ano cerca de 3.980 e 7.031 toneladas de frutas destinadas ao mercado de frutas frescas e de pêssegos em calda, respectivamente (Agrianual, 2005). Assim, verifica-se grande

1 Recebido para publicação em 3.4.2006 e na forma revisada em 4.8.2006.

2 Eng.-Agr., M.S., Doutorando em Fitotecnia, Departamento de Fitotecnica, Universidade Federal de Viçosa - DFT/UFV, 36570.000 Viçosa-MG, Bolsista CNPq, <ltuffi@ yahoo.com.br>; <americowagner@ibest.com.br>. ${ }^{3}$ Graduando do curso de Agronomia - UFV; ${ }^{4}$ Eng.-Agr., Mestrando em Fitotecnia - DFT/UFV; ${ }^{5}$ Professor Titular do Departamento de Fitotecnia - DFT/UFV. 
potencial de mercado para esta cultura, uma vez que a produção nacional ainda não atingiu volume suficiente para atender à demanda interna. Nesse sentido, o crescimento da persicultura brasileira depende de muitos fatores, principalmente no que diz respeito à adoção de técnicas de manejo e cultivo adequadas em todas as etapas do processo de produção, assegurando, assim, a obtenção de frutas de qualidade.

Dentre os tratos culturais, as plantas daninhas podem ser consideradas um dos principais problemas na condução do pomar, uma vez que podem acarretar sérios prejuízos na produção e qualidade dos frutos, em áreas onde são mal manejadas.

Na cultura do pessegueiro, o manejo dessas plantas pode ser feito por métodos físicos, químicos e mecânicos, isolados ou combinados (Durigan, 2001). O uso do controle químico destaca-se por ser mais eficiente e rápido, disponibilizando a mão-de-obra da propriedade (Martini et al., 2002) para outras atividades.

Ao optar pela utilização de determinado herbicida, devem-se avaliar os riscos e benefícios do uso do produto, considerando-se a forma de uso, a importância econômica e a presença de culturas vizinhas suscetiveis (Timossi \& Alves, 2001) e a própria cultura, no caso de herbicidas não-seletivos. Segundo Durigan (1989), quando se aplica determinado herbicida, geralmente, busca-se colocar a quantidade certa de ingrediente ativo no alvo desejado, com máxima eficiência e de maneira mais econômica possivel, sem afetar o meio ambiente.

O glyphosate está entre os herbicidas mais utilizados na fruticultura (Derr, 2001a). Entretanto, esse herbicida apresenta baixa eficiência no controle de algumas espécies daninhas, sendo necessária a busca por outros produtos para o manejo destas. O triclopyr, apesar de não registrado para a cultura do pessegueiro, é seletivo em aplicações dirigidas, apresentando-se como alternativa complementar ao glyphosate, principalmente no controle de plantas daninhas perenes. Ambos são herbicidas cuja deriva pode causar danos às plantas de pessegueiro, sobretudo no início de seu desenvolvimento.

Na literatura, a deriva é abordada pelos efeitos causados pelas moléculas de herbicidas sobre a produtividade e morfologia de culturas não-alvo. Esses trabalhos envolvem o conceito de "deriva simulada", que envolve diferentes formulações de herbicidas sobre as culturas (Bailey \& Kapusta, 1993).

Outra prática muito comum adotada na cultura do pessegueiro é o uso de fungicidas para o controle de doenças. O grande número de doenças causadas pelos fungos e seus prejuízos para a cultura tornam o uso desses produtos, na grande maioria dos casos, praticamente indispensável. Contudo, as pulverizações sucessivas de fungicidas sobre as plantas podem levar à deposição de uma fina camada sobre as folhas, a qual pode funcionar como barreira físico-química à penetração do glyphosate, num possivel contato via deriva. Além disso, pouco se sabe sobre os efeitos da deriva de herbicidas em plantas de pessegueiro e de possíveis efeitos sinérgicos e/ou antagônicos entre herbicidas e fungicidas usados na cultura.

O presente trabalho teve como objetivo avaliar os efeitos da deriva de glyphosate e triclopyr durante o crescimento e desenvolvimento inicial de plantas de pessegueiro, bem como o comportamento destas quando submetidas à deriva de glyphosate com prévio tratamento fungicida.

\section{MATERIAL E MÉTODOS}

Os trabalhos foram divididos em dois experimentos, sendo estes realizados em casa de vegetação pertencente ao Setor de Fruticultura, Departamento de Fitotecnia, da Universidade Federal de Viçosa, durante o período de agosto a outubro de 2005.

Foram utilizadas plantas jovens de pessegueiro do cultivar 'Campinas-1', cultivadas em recipientes plásticos $(3 \mathrm{~L}-32 \mathrm{~cm} \times 16 \mathrm{~cm})$, contendo como substrato a mistura de Latossolo Vermelho + Plantmax $\square-3: 1 \mathrm{v} / \mathrm{v}$, enriquecido com $\mathrm{P}_{2} \mathrm{O}_{5}\left(3,0 \mathrm{~kg} \mathrm{~m}^{-3}\right)$. Anteriormente, as sementes desse material haviam sido estratificadas em câmara fria com temperatura constante de $5{ }^{\circ} \mathrm{C}$, onde permaneceram até a emissão da radícula.

\section{Experimento 1}

O experimento 1 teve como finalidade estudar o efeito da deriva de glyphosate e 
triclopyr no crescimento e desenvolvimento de pessegueiro, de agosto a setembro de 2005.

Os tratamentos foram aplicados quatro meses após a semeadura, sendo nesse momento avaliado o comprimento aéreo $(\mathrm{cm})$ inicial das plantas, o qual apresentou média de $78,31 \mathrm{~cm}$.

Foi utilizado o delineamento em blocos casualizados, com quatro repetições, considerando-se como unidade experimental cada planta. A simulação da deriva foi feita por aplicação de doses reduzidas dos herbicidas glyphosate e triclopyr e pela mistura de ambos, constituindo os tratamentos dispostos na Tabela 1. No tratamento testemunha somente foi feita aplicação de água destilada.

No momento da aplicação dos tratamentos a umidade relativa do ar encontrava-se a 70\%, com temperatura de $25^{\circ} \mathrm{C}$ e ausência de ventos.

Tabela 1 - Doses aplicadas em pessegueiro, simulando a deriva de glyphosate e triclopyr

\begin{tabular}{|c|c|c|}
\hline Tratamento & $\begin{array}{l}\text { Glyphosate } \\
\left(\mathrm{g} \text { i.a. } \mathrm{ha}^{-1} \text { ) }\right.\end{array}$ & $\begin{array}{c}\text { Triclopyr } \\
\left.\left(\text { g i.a. }^{-1}\right){ }^{-1}\right)\end{array}$ \\
\hline 1 & 43,2 & - \\
\hline 2 & 86,4 & - \\
\hline 3 & 172,8 & - \\
\hline 4 & 345,6 & '"'-' \\
\hline 5 & - & 14,4 \\
\hline 6 & - & 28,8 \\
\hline 7 & - & 57,6 \\
\hline 8 & - & 115,2 \\
\hline 9 & 43,2 & 24,4 \\
\hline 10 & 86,4 & 28,8 \\
\hline 11 & 172,8 & 57,6 \\
\hline Testemunha & - & - \\
\hline
\end{tabular}

\section{Experimento 2}

Neste experimento avaliou-se a intoxicação causada pela deriva simulada de glyphosate em pessegueiros previamente tratados com oxicloreto de cobre, através do uso do fungicida Cuprogarb $350^{\circledR}$, de setembro a outubro de 2005.

Foram realizadas duas pulverizações com fungicida, aos 18 e 4 dias anteriores à aplicação do herbicida. Em ambas as pulverizações, utilizaram-se $20 \mathrm{~mL}$ por planta, na dose de $350 \mathrm{~g} 100 \mathrm{~L}^{-1}$ de água. As doses de glyphosate foram aplicadas cinco meses após a semeadura, sendo também avaliado o comprimento aéreo $(\mathrm{cm})$ inicial das plantas, que apresentou média de 76,71 cm.

Utilizou-se o delineamento em blocos casualizados, num fatorial $2 \times 6$ (fungicida $\mathrm{x}$ doses de glyphosate), com quatro repetições, sendo cada planta considerada uma parcela experimental.

Os dois niveis adotados no fator fungicida foram a ausência e presença da aplicação. Já as doses de glyphosate testadas foram: 0; 43,$2 ; 86,4 ; 129,6 ; 172,8$; e 345,6 g e.a. ha-1, correspondentes a $0,3,6,9,12$ e 24\% da dose de $1.440 \mathrm{~g}$ e.a. ha ${ }^{-1}$ da formulação sal de isopropilamina, respectivamente. A dose de $1.440 \mathrm{~g} \mathrm{ha}^{-1}$ de glyphosate é eficiente para o controle de grande número de espécies daninhas. No momento da aplicação do herbicida a umidade relativa do ar encontrava-se a $82 \%$ e a temperatura era de $25,5^{\circ} \mathrm{C}$.

Nos dois experimentos, a aplicação do herbicida foi feita de modo que não atingisse o terço superior das plantas. Nas aplicações, utilizou-se pulverizador costal de precisão, munido de barra com dois bicos com pontas do tipo leque TT 110.02, espaçadas de 0,5 m, operando a $250 \mathrm{kPa}$ de pressão e trabalhando com volume de calda correspondente a $200 \mathrm{~L} \mathrm{ha}^{-1}$. As folhas das plantas permaneceram, 24 horas após a aplicação, protegidas do contato com água da chuva ou proveniente da irrigação, visando evitar a lavagem dos produtos. Após a aplicação dos herbicidas foram observadas, diariamente, alterações morfológicas na parte aérea das plantas. Aos 15, 30 e 45 dias após a aplicação (DAA), determinou-se a porcentagem de intoxicação em relação à testemunha, em que 0\% corresponde à ausência de sintomas visiveis e 100\% à morte das plantas (Frans, 1972).

Aos 45 DAA, avaliaram-se, nos dois experimentos, os comprimentos da parte aérea, da raiz e total $(\mathrm{cm})$, o diâmetro do caule ( $\mathrm{mm})$, o número de ramificações primárias, a massa da matéria seca da parte aérea e da raiz das plantas (g). 
O comprimento da parte aérea, obtido no início do experimento, foi subtraído do valor avaliado aos 45 DAA, determinando-se o ganho em altura por planta após a exposição à deriva, sendo denominado de crescimento da parte aérea.

Os dados foram submetidos à análise de variância, e as médias comparadas a 5\% de probabilidade pelo teste de Tukey, por meio do programa computacional SANEST (Zonta \& Machado, 1984). Os dados de porcentagem de intoxicação foram transformados previamente em arco seno $\sqrt{\mathrm{x} / 100}$, e o número de ramificações, em $\sqrt{\mathrm{x} \square 1}$.

\section{RESULTADOS E DISCUSSÃO}

\section{Experimento 1}

Plantas tratadas com glyphosate apresentaram murcha, clorose e necrose, sintomas verificados a partir do 6o DAA, mais pronunciados nas doses superiores a 172,8 $\mathrm{g} \mathrm{ha}^{-1} \mathrm{de}$ glyphosate. Sintomas foliares semelhantes foram observados em outras culturas submetidas à deriva simulada com glyphosate, como eucalipto (Tuffi Santos et al., 2005), milho (Magalhães et al., 2001a, b) e algodão (Miller et al., 2004; Yamashita \& Guimarães, 2005).
Os sintomas observados em plantas expostas à aplicação do triclopyr, caracterizados por retorcimento dos ápices e epinastia das folhas, foram mais precoces que os observados em plantas tratadas com glyphosate.

A intoxicação das plantas variou de acordo com as doses dos herbicidas testados $(\mathrm{p}<0,05)$ aos 15, 30 e 45 DAA, sendo tanto maior quanto maiores as doses de glyphosate, triclopyr e de suas misturas (Tabela 2).

Plantas tratadas com doses de 345,6 $\mathrm{g}^{\mathrm{ha}^{-1}}$ de glyphosate e de 57,6 $\mathrm{g} \mathrm{ha}^{-1}$ de triclopyr apresentaram os maiores percentuais de intoxicação (Tabela 2), enquanto as misturas dos dois herbicidas não mostraram efeitos sinérgicos quanto à intoxicação do pessegueiro.

A análise de variância de comprimentos total $(\mathrm{CT})$, da parte aérea (CPA) e de raiz (CR), crescimento da parte aérea (CRPA), diâmetro do caule (DC), número de brotações primárias (NBP) e massa da matéria seca da parte aérea (MMSPA) e de raiz (MMSR) mostrou semelhanças significativas $(p>0,05)$ entre os tratamentos testados (Tabela 3).

Os resultados demonstram que, apesar dos sintomas de intoxicação verificados, as doses dos herbicidas aplicados simulando uma deriva não afetaram o desenvolvimento das plantas.

Tabela 2 - Porcentagem de intoxicação de plantas de pessegueiro submetidas à deriva de glyphosate e triclopyr, aos 15, 30 e 45 dias após aplicação (DAA)

\begin{tabular}{|c|c|c|c|c|}
\hline \multirow{2}{*}{ Tratamento } & \multirow{2}{*}{$\begin{array}{c}\text { Dose } \\
\left(\mathrm{g} \mathrm{ha}^{-1}\right)\end{array}$} & \multicolumn{3}{|c|}{$\%$ de intoxicação } \\
\hline & & 15 DAA & 30 DAA & 45 DAA \\
\hline Glyphosate & 43,2 & $0,00 \mathrm{~b}^{*}$ & $1,25 \mathrm{c}$ & $1,25 \mathrm{~b}$ \\
\hline Glyphosate & 86,4 & $9,50 \mathrm{~b}$ & $10,00 \mathrm{bc}$ & $15,00 \mathrm{ab}$ \\
\hline Glyphosate & 172,8 & $20,00 \mathrm{ab}$ & $22,50 \mathrm{ab}$ & $21,00 \mathrm{ab}$ \\
\hline Glyphosate & 345,6 & $30,00 \mathrm{a}$ & $35,00 \mathrm{a}$ & $35,00 \mathrm{a}$ \\
\hline Triclopyr & 14,4 & $8,75 \mathrm{~b}$ & $3,50 \mathrm{c}$ & $0,00 \mathrm{~b}$ \\
\hline Triclopyr & 28,8 & $9,50 \mathrm{~b}$ & $10,75 \mathrm{bc}$ & $3,25 \mathrm{~b}$ \\
\hline Triclopyr & 57,6 & $15,00 \mathrm{ab}$ & $12,00 \mathrm{bc}$ & $13,75 \mathrm{ab}$ \\
\hline Triclopyr & 115,2 & $18,75 \mathrm{ab}$ & $30,00 \mathrm{ab}$ & $35,00 \mathrm{a}$ \\
\hline Glyphosate + triclopyr & $43,2+24,4$ & $22,00 \mathrm{ab}$ & $32,50 \mathrm{ab}$ & $27,00 \mathrm{a}$ \\
\hline Glyphosate + triclopyr & $86,4+28,8$ & $20,00 \mathrm{ab}$ & $17,50 \mathrm{abc}$ & $13,75 \mathrm{ab}$ \\
\hline Glyphosate + triclopyr & $172,8+57,6$ & $22,50 \mathrm{ab}$ & $28,75 \mathrm{ab}$ & $22,50 \mathrm{ab}$ \\
\hline Testemunha & - & $0,00 \mathrm{~b}$ & $0,00 \mathrm{c}$ & $0,00 \mathrm{~b}$ \\
\hline $\mathrm{CV}(\%)$ & - & 32,01 & 73,49 & 35,96 \\
\hline
\end{tabular}

* Médias seguidas pela mesma letra não diferem significativamente entre si pelo teste de Tukey a 5\% de probabilidade. 
Tabela 3 - Comprimentos total (CT), da parte aérea (CPA) e de raiz (CR), crescimento da parte aérea (CRPA), diâmetro do caule (DC), número de brotações primárias (NBP) e massa da matéria seca da parte aérea (MMSPA) e de raiz (MMSR) das plantas jovens de pessegueiro, em 12 tratamentos simulando a deriva de glyphosate e triclopyr

\begin{tabular}{|c|c|c|c|c|c|c|c|c|c|}
\hline Tratamento & $\begin{array}{c}\text { Dose } \\
\left(\mathrm{g} \mathrm{ha}^{-1}\right)\end{array}$ & $\begin{array}{l}\mathrm{CT} \\
(\mathrm{cm})\end{array}$ & $\begin{array}{l}\mathrm{CPA} \\
(\mathrm{cm}) \\
\end{array}$ & $\begin{array}{l}\mathrm{CR} \\
(\mathrm{cm}) \\
\end{array}$ & $\begin{array}{c}\text { CRPA } \\
(\mathrm{cm})\end{array}$ & $\begin{array}{c}\text { DC } \\
(\mathrm{mm})\end{array}$ & NBP & $\begin{array}{c}\text { MMSPA } \\
(\mathrm{g})\end{array}$ & $\begin{array}{c}\text { MMSR } \\
(\mathrm{g})\end{array}$ \\
\hline Glyphosate & 43,2 & 113,00 & 81,63 & 31,38 & 8,63 & 5,95 & 30,68 & 18,20 & 6,20 \\
\hline 'Glyphosate & 86,4 & 116,50 & 86,13 & 30,38 & 11,13 & 5,95 & 26,13 & 19,03 & 5,30 \\
\hline Glyphosate & 172,8 & 124,50 & 91,63 & 32,88 & 12,13 & 5,96 & 24,52 & 15,30 & 5,40 \\
\hline Glyphosate & 345,6 & 113,63 & 83,00 & 30,63 & 4,75 & 6,18 & 29,47 & 18,30 & 4,55 \\
\hline Triclopyr & 14,4 & 116,50 & 83,63 & 32,88 & 3,38 & 6,05 & 31,07 & 19,65 & 6,60 \\
\hline Triclopyr & 28,8 & 119,50 & 91,75 & 27,75 & 13,25 & 5,63 & 30,03 & 16,13 & 4,60 \\
\hline "Triclopyr & 57,6 & 115,25 & 84,00 & 31,25 & 12,00 & 6,06 & 21,83 & 17,22 & 5,13 \\
\hline Triclopyr & 115,2 & 120,63 & 90,00 & 30,63 & 6,50 & 5,96 & 29,58 & 16,43 & 5,38 \\
\hline Glyphosate + triclopyr & $43,2+14,4$ & 127,25 & 97,00 & 30,25 & 7,50 & 6,62 & 32,35 & 21,78 & 6,75 \\
\hline Glyphosate + triclopyr & $86,4+28,8$ & 120,13 & 91,75 & 28,38 & 11,25 & 6,20 & 25,20 & 16,55 & 4,85 \\
\hline Glyphosate + triclopyr & $172,8+57,6$ & 118,25 & 89,00 & 29,25 & 14,50 & 5,93 & 26,37 & 18,05 & 4,78 \\
\hline Testemunha & - & $116,75 \mathrm{~ns}$ & $86,10 \mathrm{~ns}$ & $30,63 \mathrm{~ns}$ & $10,88 \mathrm{~ns}$ & $5,93 \mathrm{~ns}$ & $31,06 \mathrm{~ns}$ & $16,83 \mathrm{~ns}$ & $4,70 \mathrm{~ns}$ \\
\hline $\mathrm{CV}(\%)$ & - & 6,71 & 8,96 & 10,48 & 73,19 & 7,86 & 10,84 & 17,94 & 35,53 \\
\hline
\end{tabular}

ns não-significativo pelo teste $\mathrm{F}$ a $5 \%$ de probabilidade.

Em eucalipto, plantas submetidas a 172,8 e $345,6 \mathrm{~g} \mathrm{ha}^{-1}$ de glyphosate apresentaram menores altura, diâmetro e matéria seca, ocasionados pelas injúrias severas que levaram à morte dos ponteiros, senescência foliar e, conseqüentemente, ao não-crescimento (Tuffi Santos et al., 2006).

O herbicida triclopyr, apesar de não registrado, mostrou-se pouco tóxico para a cultura do pessegueiro, apresentando boa eficiência de controle sobre muitas espécies de plantas daninhas. Este fato está de acordo com os resultados de Derr (2001b), em que o autor sugere o uso deste produto, em aplicações dirigidas, para macieira. Esses dados podem ser úteis para aprovação da extensão do uso desse produto para pessegueiro.

\section{Experimento 2}

Os sintomas de intoxicação foram semelhantes aos descritos para plantas tratadas com glyphosate no experimento 1 , não havendo diferença visual entre plantas tratadas ou não com fungicida.

A intoxicação das plantas variou de acordo com as doses dos herbicidas testados $(p<0,05)$ aos 15, 30 e 45 DAA. A porcentagem de intoxicação foi significativamente diferente $(\mathrm{p}<0,05)$ nas plantas tratadas ou não com fungicida aos 45 DAA, o que não foi verificado nas demais épocas de avaliação $(p>0,05)$.
A interação fungicida $\mathrm{x}$ doses de glyphosate não foi significativa $(P>0,05)$ entre os tratamentos em todas as épocas de avaliação.

Maiores notas de intoxicação foram observadas em plantas de pessegueiro pulverizadas com a maior dose de glyphosate (345,6 $\left.\mathrm{g} \mathrm{ha}^{-1}\right)$, em todas as épocas de avaliação, apresentando, aos 45 DAA, 37,5 e 41,23\% de intoxicação nas plantas pulverizadas e não-pulverizadas com fungicida, respectivamente (Figura 1).

Em todas as épocas de avaliação, a porcentagem de intoxicação das plantas tratadas com fungicida foi ligeiramente superior á das nãotratadas (Figura 1). Tal fato pode significar um efeito sinérgico entre os defensivos aplicados, onde o oxicloreto de cobre está potencializando os efeitos negativos da deriva de glyphosate no pessegueiro.

De acordo com os resultados obtidos, observou-se efeito significativo na interação fungicida $\mathrm{x}$ doses de glyphosate para o comprimento total dos pessegueiros (Figura 2A, B).

Na Figura 2A, o comprimento total das plantas de pessegueiro com a aplicação prévia de fungicida demonstrou comportamento quadrático, com ponto de máxima correspondente à dose de 93,5 $\mathrm{g} \mathrm{ha}^{-1}$ de glyphosate. Já quando não se utilizou a aplicação do fungicida, as doses do herbicida não influenciaram significativamente o comprimento total das plantas. 

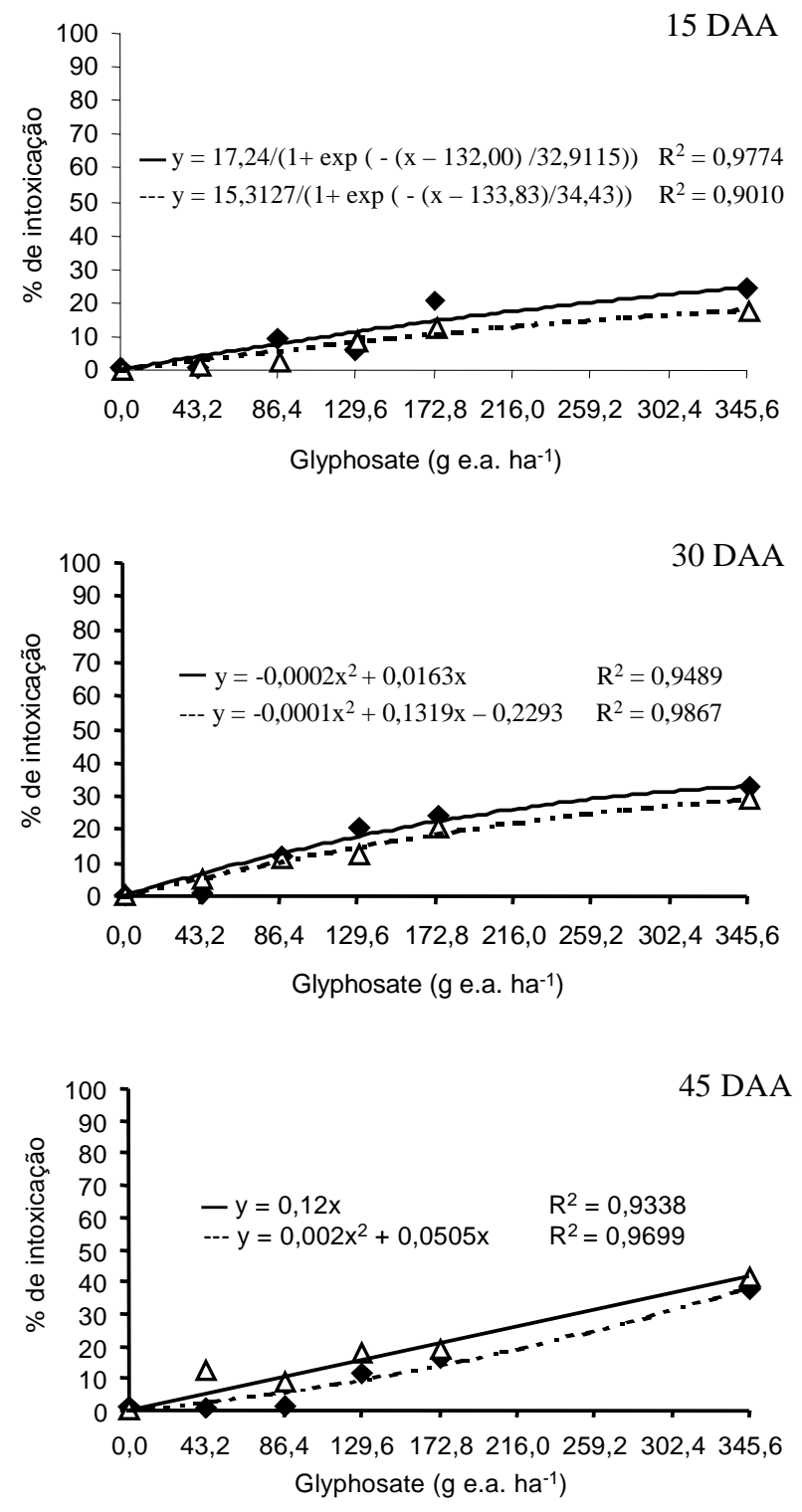

Figura 1 - Porcentagem de intoxicação das plantas jovens de pessegueiro submetidas à deriva do glyphosate com (-----) e sem (—) pulverização prévia de fungicida, aos 15, 30 e 45 dias após aplicação (DAA).

Supõe-se que a maior intoxicação obtida, quando da aplicação conjunta de herbicida + fungicida (Figura 1), tenha afetado o crescimento dos pessegueiros.

As doses de glyphosate influenciaram $(\mathrm{P}<0,05)$ o comprimento total (Figura 3A), o número de ramificações primárias (Figura 3B) e a massa da matéria seca da parte aérea (Figura 3C) e de raiz (Figura 3D) dos pessegueiros. Já nas demais variáveis, as doses
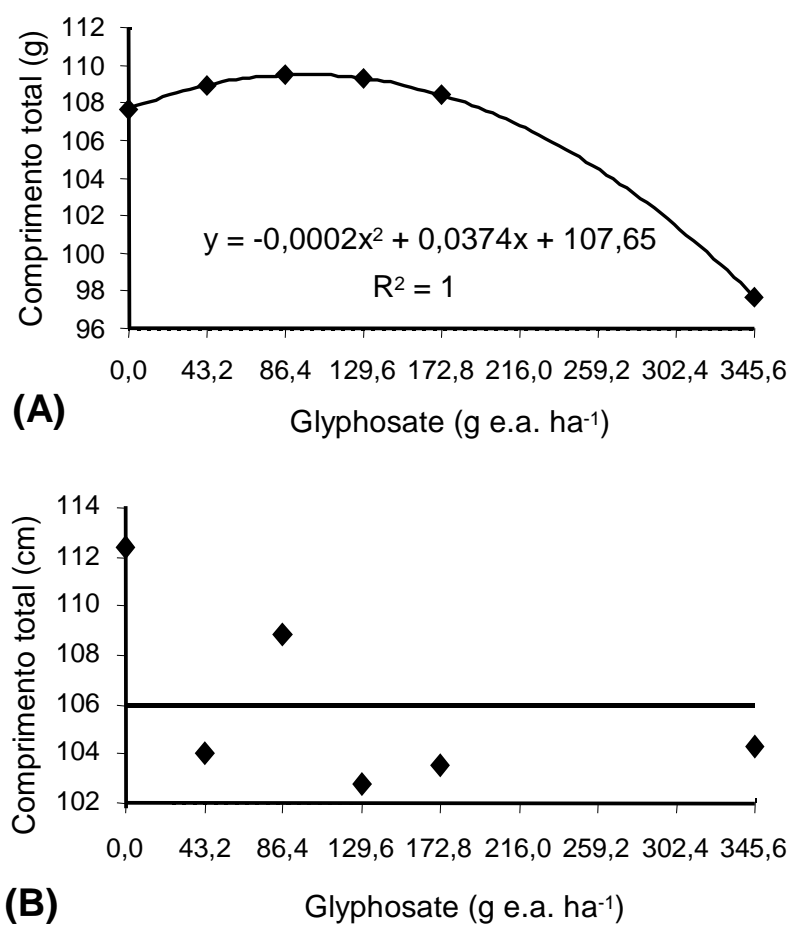

Figura 2 - Comprimento total do pessegueiro sob deriva de glyphosate nos tratamentos com (A) e sem (B) aplicação prévia de fungicida.

deste herbicida não provocaram diferenças significativas $(\mathrm{P}>0,05)$.

Com a simulação da deriva de glyphosate, observou-se comportamento linear decrescente para comprimento total (Figura 3A), número de brotações primárias (Figura 3B) e massa da matéria seca da parte aérea (Figura 3C) e de raiz (Figura 3D), à medida que se aumentou a dose deste herbicida.

Desse modo, pode-se comprovar a importância dos cuidados com aplicação dirigida de glyphosate para o controle de plantas daninhas na cultura do pessegueiro, bem como com a aplicação em áreas vizinhas aos pomares. Cuidados com a tecnologia de aplicação e com as doses recomendadas devem ser tomados, buscando minimizar os riscos com a deriva acidental deste herbicida, a qual poderá acarretar prejuízos ao desenvolvimento das plantas de pessegueiro, seja em viveiro ou pomar comercial.

Em macieira, Rom et al. (1974) verificaram que o glyphosate, quando absorvido pelas folhas, é translocado na planta, até as gemas, 

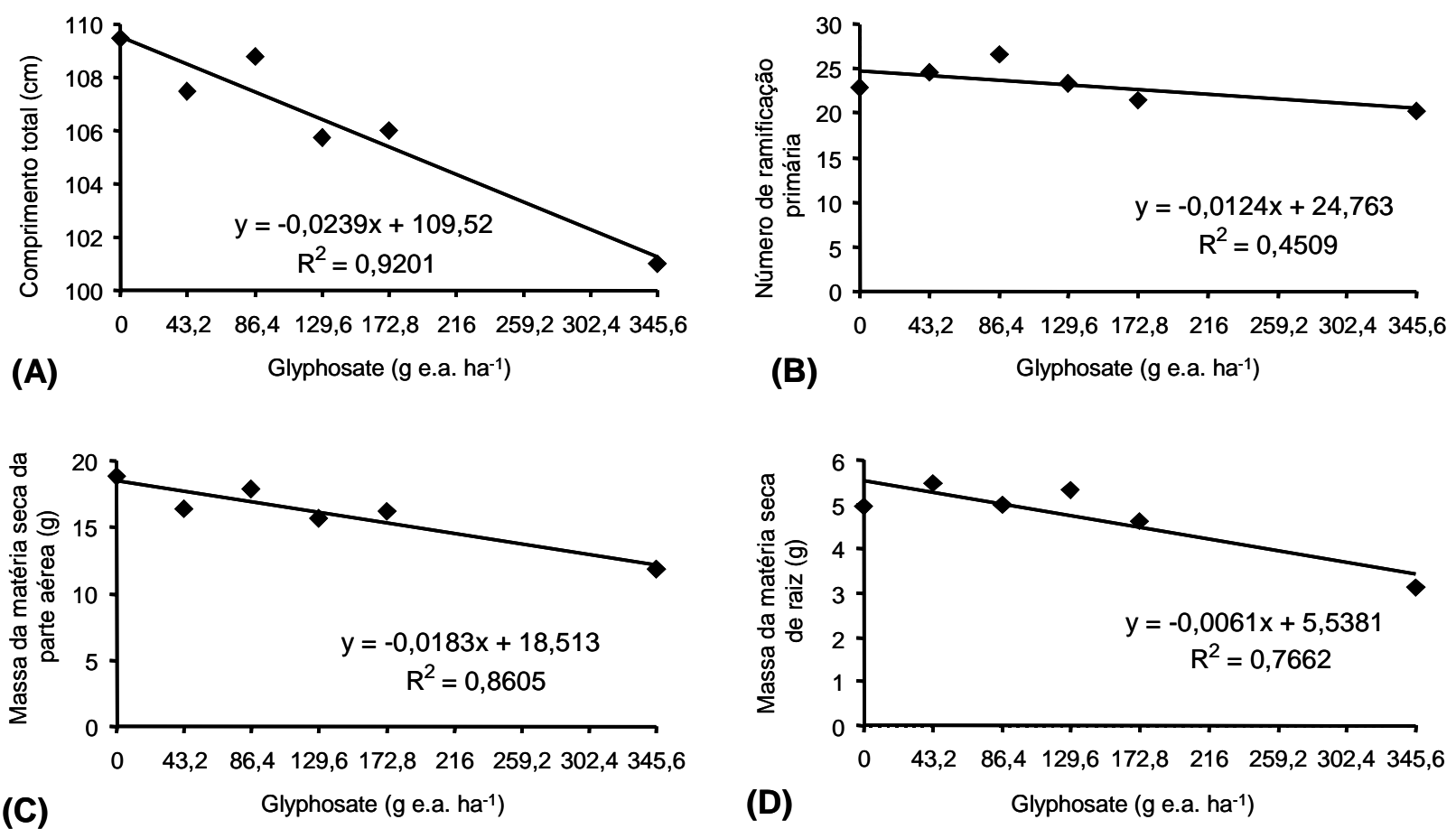

Figura 3 - Comprimento total (A), número de ramificações primárias (B) e massa da matéria seca da parte aérea (C) e de raiz (D) de pessegueiro submetido à deriva de glyphosate.

manifestando os sintomas de expressão na brotação. Acredita-se que o maior número de ramificações primárias com uso de menor dose se deva à inibição da brotação com a utilização de maiores doses do glyphosate simulando deriva.

$\mathrm{O}$ fator fungicida apresentou diferenças significativas apenas para porcentagem de intoxicação aos 45 DAA, não influenciando o crescimento e desenvolvimento dos pessegueiros.

Conclui-se, pelo experimento 1 , que plantas jovens de pessegueiro tratadas com doses de 345,6 $\mathrm{g} \mathrm{ha}^{-1}$ de glyphosate e de $57,6 \mathrm{~g} \mathrm{ha}^{-1}$ de triclopyr em deriva simulada apresentaram os maiores percentuais de intoxicação. No entanto, não houve efeito da deriva destes herbicidas no crescimento e desenvolvimento das plantas. No experimento 2 , as doses de glyphosate aplicadas influenciaram o desenvolvimento inicial das plantas, sendo seus efeitos proporcionais ao aumento das doses. O fator fungicida não influenciou o desenvolvimento inicial dos pessegueiros. Entretanto, em todas as épocas de avaliação a porcentagem de intoxicação foi maior em plantas tratadas com oxicloreto de cobre, indicando possivel efeito sinérgico entre os defensivos testados.

\section{LITERATURA CITADA}

AGRIANUAL: Anuário de agricultura brasileira. São Paulo: FNP Consultoria e Comércio, 2005. p. 439-443.

BAILEY, J. A.; KAPUSTA, G. Soybean (Glycine max) tolerance to simulated drift of nicosulfuron and primisulfuron. Weed Technol., v. 7, n. 3, p. 740-745, 1993.

DERR, J. F. Biological assessment of herbicide use in apple production - background and current use estimates. Hort. Technol., v. 11, n. 1, p. 11-19, 2001a.

DERR, J. F. Biological assessment of herbicide use in apple production - estimated impacts following loss of specific herbicides. Hort Technol., v. 11, n. 1, p. 20-25, 2001 b.

DURIGAN, J. C. Comportamento de herbicidas no ambiente. In: SEMINÁRIO TÉCNICO SOBRE PLANTAS DANINHAS E O USO DE HERBICIDAS EM REFLORESTAMENTO, 1989, Rio de Janeiro. Anais... Rio de Janeiro: SBS/ABRACAVE/SIF, 1989. 
DURIGAN, J. C. Manejo de plantas daninhas em pomares. In: ENCONTRO NACIONAL SOBRE FRUTICULTURA DE CLIMA TEMPERADO, 4., 2001, Fraiburgo, SC.

Anais...Caçador, SC: Epagri, 2001. p. 23-27.

FRANS, R. E. Measuring plant responses. In: WILKINSON, R. E. (Ed.). Research methods in weed science. Atlanta: Southern Weed Science Society, 1972. p. 28-41.

MAGALHÃES, P. C. et al. Efeito de doses reduzidas de glyphosate e paraquat simulando deriva na cultura do milho. Planta Daninha, v. 19, n. 2, p. 247-253, 2001a.

MAGALHÃES, P. C. et al. Efeito de doses reduzidas de glyphosate e paraquat simulando deriva na cultura do sorgo. Planta Daninha, v. 19, n. 2, p. 255-262, 2001b.

MARTINI, G. et al. Eficácia de uma nova formulação de glifosato para o controle de grama-seda (Cynodon dactylon), em pomar de citros. R. Bras. Frutic., v. 24, n. 3, p. 683-686, 2002.
MILLER, D. K. et al. Response of non glyphosate resistant cotton to reduced tates of glyphosate. Weed Sci., v. 52, p. $178-182,2004$.

ROM, R. C.; BROWN, S. A.; MARKHAM, J. D. Glyphosate toxicity to apple trees. Hort Sci., v. 9, n. 6, p. 594-595, 1974.

TIMOSSI, P. C.; ALVES, P. L. C. A. Efeitos da simulação de deriva de clomazone em plantas de laranjeira 'Hamlin'.

R. Bras. Frutic., v. 23, n. 2, p. 310-314, 2001.

TUFFI SANTOS, L. D. et al. Crescimento e morfoanatomia foliar de eucalipto sob efeito de deriva do glyphosate. Planta Daninha, v. 23, n. 1, p. 133-142, 2005.

YAMASHITA, O. M.; GUIMARÃES, S. C. Resposta de cultivares de algodoeiro a subdoses de glyphosate. Planta Daninha, v. 23, n. 4, p. 627-633, 2005.

ZONTA, E. P.; MACHADO, A. A. SANEST - Sistema de Análise Estatística para Microcomputadores. Pelotas: Universidade Federal de Pelotas, 1984. 75 p. 